\title{
A Comparative Study of Chlorite Vessels Iconography, Discovered from HalilRud Basin
}

\author{
Hassan Basafa*, Mohammad Hosein Rezaei \\ University of Neyshabur, Iran \\ *Corresponding Author: hbasafa@gmail.com
}

Copyright (C 2014 Horizon Research Publishing All rights reserved.

\begin{abstract}
HalilRud drainage basin is located South-East of Iran in Kerman province with an area of 8450 square kilometers. Multiplicity of sites, hills and ancient cemeteries along with numerous findings and cultural materials is a feature of this great cultural zone. A variety of factors and appropriate conditions together with favorable environmental situation have attracted human communities and groups from the oldest ages in this great cultural sphere. In 2001 and after accidental discovery of cultural materials obtained from very rich and ancient cemeteries in HalilRud River margin, it has been revealed that the HalilRud cultural zone has been one of the largest industrial and cultural centers of Ancient East in production and export of manufactured goods in the second half of the third millennium BC. Engraved chlorite vessels and other handicraft had been exported to other urban areas of Southwest Asia and Central Asia to Syria.In this study, based on study of 144 pieces of engraved chlorite vessels fromHalilRud River zone so far introduced, it has been attempted to present a preliminary analysis of their iconography. Also, they have been briefly compared with other findings of Southeastern Iran sites such as Tape Yahya, Shahdad and Shahr-I-Sokhta.
\end{abstract}

Keywords HalilRud, Jiroft, Konar Sandal, Chlorite, Bronze Age, Tape Yahya, Shahdad, Shahr-I-Sokhta

\section{Introduction}

In 2001, after accidental discovery of material and cultural objects, hundreds of looters plundered hundreds of intact chlorite vessels decorated with symbolic motifs from the ancient rich cemeteries of HalilRud River margin and cheaply sold them to international traffickers. Follow-up of courts and capture of traffickers of cultural property has resulted in return of some of the vessels. All the seized pieces emphasized that HalilRud River cultural sphere has been one of the largest industrial and cultural centers of Ancient East in production and export of manufactured goods especially chlorite vessels in the second half of the third millennium BC. Iconography of chlorite vessels found in HalilRud River cultural sphere is very rich and complex and is drawn from the rich mythology and ideological concepts of the people in this cultural domain. The vessels in this period of time have been such valuable that many of them have been exported to other Southwest Asia urban centers from CentralAsia to Syria.

In this research we have attempted to separate and study chlorite container motifs so far introduced (Majidzade 2003 and 2006; Iran Bastan Museum 2005), and while introducing them, present a preliminary analysis of rich iconography of vessels and briefly compare them with other sites Southeastern Iran such as TepeYahya, Shahdad and Shahr-I-Sokhta.

\section{Topographic Description of HalilRud Valley in Jiroft}

In terms of geographical location, Jiroft County, as a county in Kerman province is located in $56^{\circ} 45^{\prime}$ to $58^{\circ} 31^{\prime} \mathrm{N}$ $28^{\circ} 10^{\prime}$ to $29^{\circ} 20^{\prime} \mathrm{E}$ coordinates. It has an area of 13798.619 square kilometers. Jiroft has a plain and mountain situation and HalilRud River is its most important river (Geographical atlas of Kerman Province, 2003, 3).

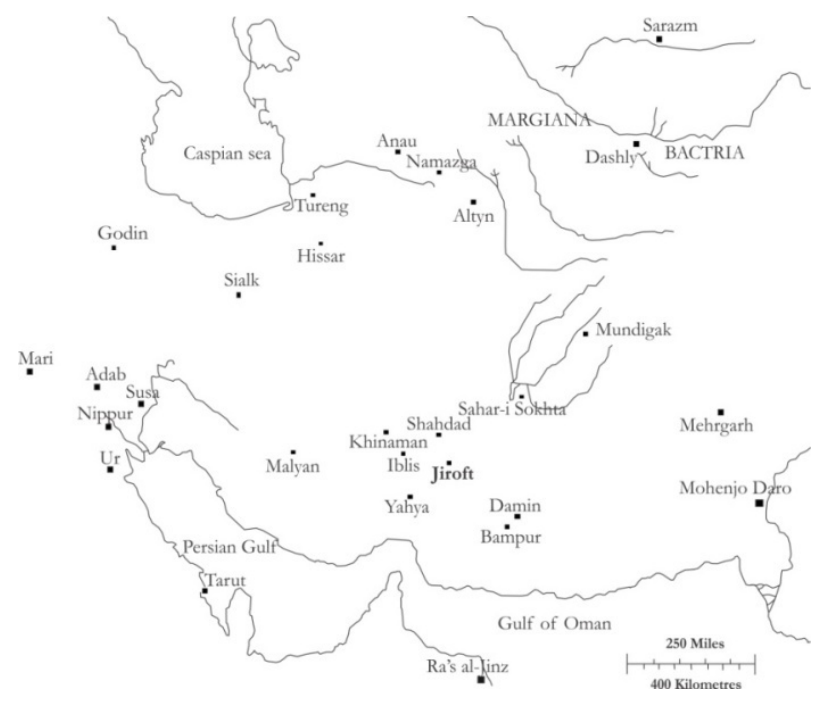

Figure 1. Location of Jiroft at Iran

HalilRud River drainage basin with an area of 8.380 hectares, with North West - South East direction with 400 $\mathrm{km}$ length begins from Zagros Mountains in the north of 
Jiroft and ends in Jazmurian basin (Jafari, 1997, 45-47) The average height between Jiroft and Jazmurian basin inlet is 550 meters. The valley is surrounded with high mountains, and downstream Jiroft River there is an alluvial plain with a width of seven kilometers drained by two main drainage channels (Fig. 1). Archaeological areas identified in HalilRud River of which north and south Konar Sandal hills are the most important, are all located in the alluvial plain a few meters higher than flood level of HalilRud River (Fouache, 2005, 109).

\section{Research Background}

So far, distribution, organization of production and consumption of engraved chlorite vessels of the second half of the third millennium B.C. has been analyzed by several researchers. Kohl is one of the first researchers to study these vessels, and for this purpose he has benefited from intercultural style (Kohl, 1974). Miroschedi is another researcher treating Louvre Museum chlorite vessels and has applied the terms "ancient series" and a "recent series" (1973, 9-77). Although his classification must be revised, it is still the basis for many archaeologists. Lamberg-Karlovsky, like Kohl, has chosen the intercultural style to define the chlorite vessels found in Southwest Asia sites (Lamberg-Karlovsky, 1988, 55 - 68).

Cleuziou is another researcher who has briefly studied HalilRud River vessels and their relation with Tarut collection in southern Persian Gulf region (Cleuziou, 2003, 114-125). Jean Perrot in 2003 (Perrot, 2003, 96-114) and in 2005 together with YousefMajidzadeh (Perrot\&Madjidzadeh, 2005, 123-152) have dealt with iconography of vessels found in HalilRud River.

\section{HalilRud River Chlorite Vessels}

Although many of chlorite vessels are a result of unauthorized excavations and have not been obtained by scientific explorations, they indicate flourishing HalilRud River culture of the third and second millennia BC. Researchers already have very different views in this regard, and even some of them (Muscarella, 2004, 173-198; Kohl, 2004, 287) have been suspicious of Jiroft findings and have recognized most of them as fake. At present, 144 pieces of carved chlorite vessels of HalilRud River zone in Jiroft have been introduced in two catalogs and a brochure (Majidzade, 2003 and 2006; National Museum Catalog 2005), the analysis of iconography of which has been dealt with in this research.

Chlorite vessels of HalilRud River have considerable variety in shape. The most important forms are cylindrical vases, cone carafes, cups, ventricular jugs, handbag shape (weight stone), game object, bowls and various other forms (Majidzadeh, 2003).

One of the most important characteristics of stone vessels discussed is the use of decorated stone. This technique is so advanced that almost all the eyes of human or animal figures have been stone decorated. There are some rules and principles of this technique, for example, stone decoration in the eyes of wild and carnivorous animals like eagle, snake, leopard and lion is circular but it is oval for domestic animals such as herbivores and ibex, cattle and also in humans. White marble or calcareous or turquoise has been used for eyes. In some of the samples the white of the leopard eye is made from ochre colored stone and the black of eyes with turquoise (Majidzade, 2003, 3).

\section{Iconography of Chlorite Vessels in HalilRud Basin}

Iconography of chlorite vessels found in the cemeteries of HalilRud River in Jiroft is too rich and complex that their classification and categorization in specific groups is very difficult. This is also true for interpretation of the designs and their origin. However, the motifs have been classified in seven groups. It is also essential to note that sometimes a combination of patterns also has been used (Fig. 2).

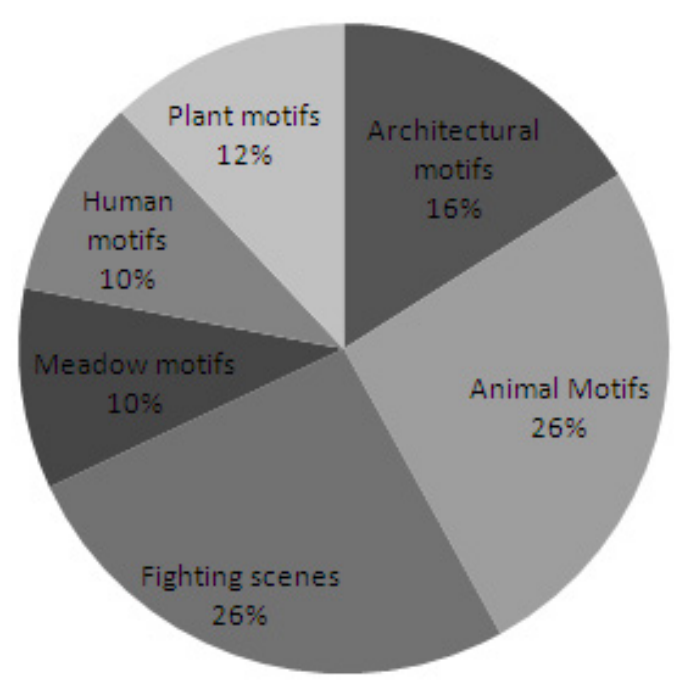

Figure 2. Percentage of Chlorite Vessels Moti

\section{Geometrical motifs}

Brick-like motifs with bezel corners (Fig. 3: 1), hair lock texture design (Fig. 3: 2), fish scales, rope design (Fig. 3: 3), spiral (Fig. 3: 4), basket design (Fig. 3: 5) and circle or concentricity with a point in the middle (Fig. 3: 6) are among geometric designs. Among these design patterns, rope design reminds of river, and imagination of the artist has progressed to the point that they have used rope like wave lines.

Geometric motifs have also been found in other Southeastern sites in Iran but their frequency in Jiroft is much higher. Brick like design in TepeYahya (Lamberg-Karlovsky, 1988, Fig. 3, K) and the Shahdad area (Hakemi, 1972, 11, A); hair like texture in TepeYahya (Lamberg-Karlovsky, 1988, Fig. 3, B); fish scales in the Shahr-I-Sokhta (Kohl, 1977, 24, n 2) and basket design in TepeYahya (Lamberg-Karlovsky, 1988, Fig. 3, C); basket design in TepeYahya (Lamberg-Karlovsky, 1988, Fig. 4, I) and Shahdad area (Hakemi, 1972, 142) and circle or concentricity designs with a point in the middle in Shahdad area (Hakemi, 1972, 132) is seen. 

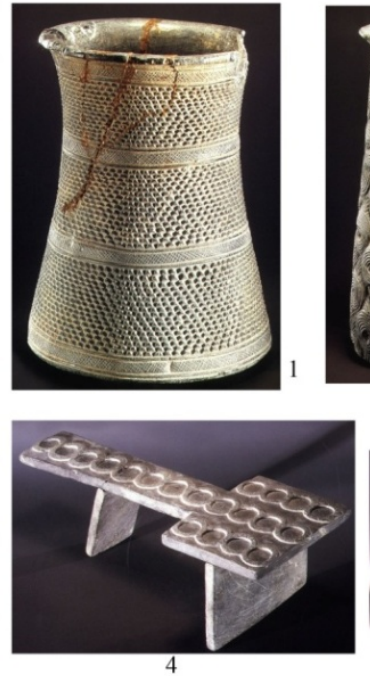
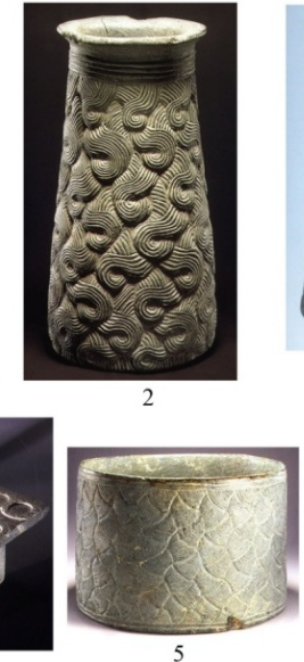

2
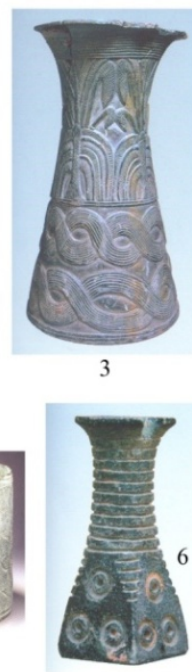

Figure 3. 1- Conical vase with brick-like motifs (Piran and Hesari, 2005, Fig. 8); 2- Conical vase with hair lock texture design (Piran and Hesari, 2005, Fig. 6); 3- Conical vase with rope design and palms (Majidzade, 2003, 110); 4- Game object with spiral design (Piran and Hesari, 2005, Fig. 24); 5Cylindrical vase with basket design (Piran and Hesari 2005, Fig. 12); 6Kohl vase with and circle or concentricity with a point in the middle (Majidzade, 2003, 120).

\section{Fighting scenes}

Another design on stone vessels is fighting scene that without doubt has been attractive for ancient HalilRud River people, because it has been frequently used by them. Issues such as snake and leopard fight (Fig. 4: 1), snake and eagle fight (Fig. 4: 2), and battle of intertwined snakes (Fig. 4: 3) and bull attack to lion (Fig. 4: 4) are placed in this group.

The theme of snake and leopard fight has also been observed in TepeYahya (Lamberg-Karlovsky, 1988, Fig. 3, $\mathrm{G})$. However, confrontation of two wild animals in Sumerian art was common, but a specific form of it unique to New Uruk period and observed on cylindrical seals is the fighting scene of two animals whose long tails or necks are intertwined in each other (Majidzadeh, 2003, 4-5). Bull attack to lion motif is interesting because it is unique to Jiroft designs.

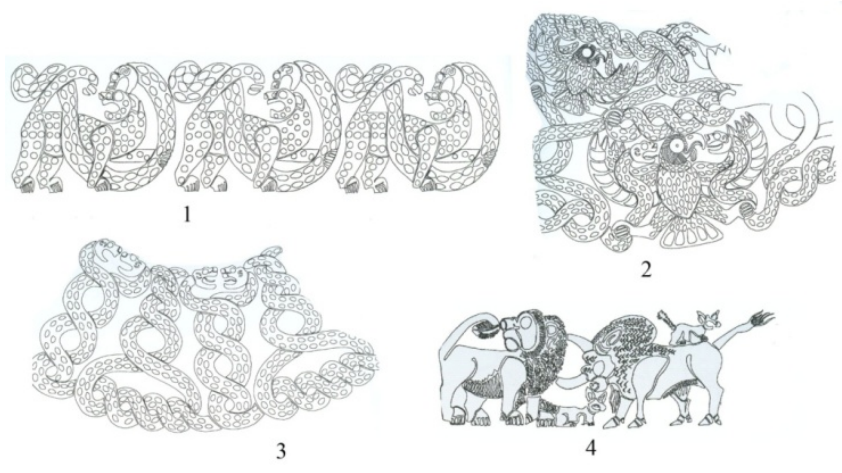

Figure 4. 1- Fighting scene between snake and tiger (Majidzade, 2003, 80); 2- Fighting scene between snake and eagle (Majidzade, 2003, 92-94); 3 battle of intertwined snakes (Majidzade, 2003, 99-100); 4- bull attack to lion (Majidzade, 2003, 58-59).

\section{Animal motif}

Animal motifs that represent the fauna of the region in ancient times include scorpion (Fig. 5: 1), eagle (Fig. 5: 2), bull (Fig. 5: 3), lion (Fig. 5: 4) and the combined scorpionman design (Fig. 5: 5). Scorpion is the most common animal design used and is often seen in multiple rows (two, three and four rows). Scorpion design has also been used in many cases as a filling or combined design (Scorpion - man).

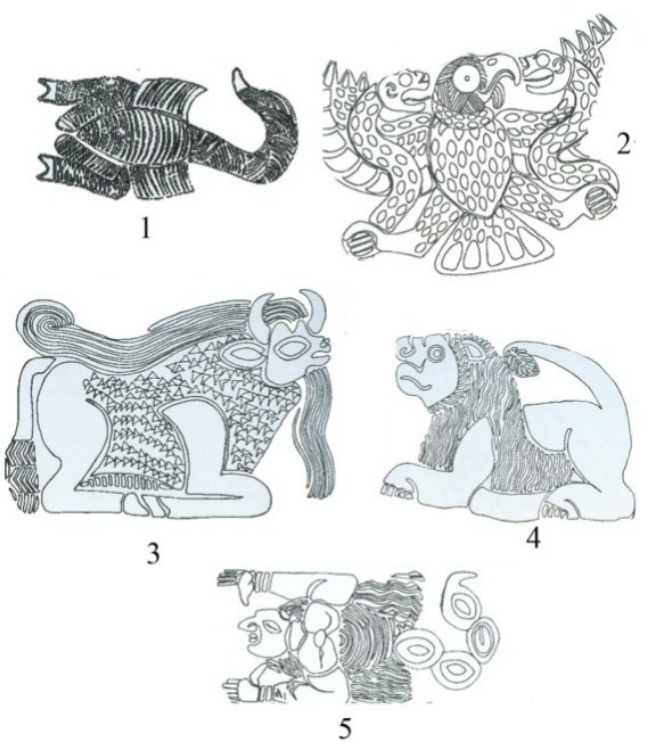

Figure 5. 1- Scorpion motive (Madjidzade, 2003, 11); 2- Eagle motive (Madjidzade, 2003, 92); 3- Bull motif (Majidzade, 2003, 53); 4- Lion motif (Majidzade, 2003, 39); Human-Scorpion motif (Majidzade, 2003, 113).
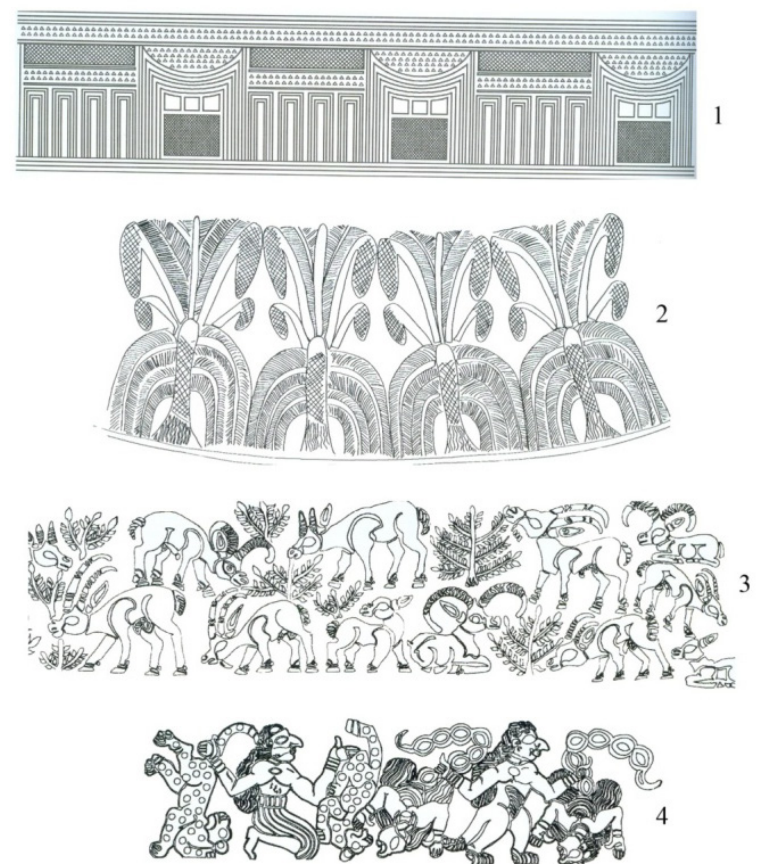

Figure 6. 1- Architectural motif (Majidzade, 2003, 69); 2- Palms (Madjizade, 2003, 110); Meadow motif (Majidzade, 2003, 18-20); A person that domesticate animals (Majidzade, 2003, 15-17).

\section{Architecture motif}

About 12 percent of total designs on chlorite vessels of HalilRud are architecture designs (Fig. 6: 1). This subject has been stereotypical and is observed in almost all of the forms. The feature of this design is downward doorways and decorative half columns or half towers. Existence of 
downward doorways has been demonstrated in the graves explored in GhaleKoochak, and many researchers have connected this type of architecture with rituals (Majidzade, 2006, 30). Decorative half towers have been observed in Mundigak in Afghanistan (Dumarcay, 1984, 47-80). Among other designs used in architecture is a step like structure topped by a horn like symbol. Stylistically, this design probably shows a commemorative tower like Mesopotamian ziggurats or something similar to what has been found in AltinTepe (Vallat, 2003, 92-97).

The architecture design also appears on other forms and sometimes as a combined design with other designs. Architectural design referred to by Kohl as supraregional (Kohl, 1974) has also been observed in sites in Southwestern Iranian plateau such as TepeYahya (Lamberg-Karlovsky, 1988, Fig. 2, H \& Pl. VII) and Shahdad (Hakemi, 1972, 193).

\section{Plant motifs}

Plant motifs are classified in two groups (Fig. 6: 2) of palm comparable to TepeYahya (Lamberg-Karlovsky, 1988, P1. VIII) and rosette. Palm has been frequently used while there have been cases combined with other designs.

\section{Meadow scene}

In another conventional design, horned herbivore animals have been displayed grazing in the prairie (Fig. 6: 3). Meadow has been a favorite topic for people in HalilRud sphere, and artists have been appropriately inspired from the natural environment and have dealt with it. In meadow scenes, some goats are seen feeding on trees. In some cases, the design has been created in duplicate, and two rows of goats are observed feeding indicating the pinnacle of artist's skill. In some cases the goats are seen rising on their hind legs or jumping. Meadow scene is among motifs specific to HalilRud River zone in Jiroft and has not been seen in other places.

A scene similar to meadow motif has been depicted on a cylindrical seal of Late Uruk period in which a man feeds the goats by tree branches. However, this design (two goats facing on the sides of a tree) has been found from Proto-Elamite, Susa III and Yahya IVC periods (Majidzadeh, 2004, 5).

\section{Human motifs}

The most important human motifs are animal taming scenes. In these designs we always see heroes raising the animal with two hands in the air. In some examples the tamer appears as a combined form of bull-man and lion-man (Fig. 6: 4). Undoubtedly, this design perhaps relates the Gilgamesh and Lugalbanda epics. Although at present just hardly can the details be reconstructed.

In Shahdad site also a sample has been found (Helwing, 2004, 160, Figs. 8-9) similar to samples near Jiroft and can be regarded as an imported from this civilization, although chemical analyses are needed to prove this theory.

In iconography of human motifs it must be stated that the bust of all men is nude and the skirt has been fastened to waist by a large shawl, with the difference that here they carry a necklace with a large earring of turquoise that extends from back to the end of waist (Majidzadeh, 2003, 4).

\section{Chronology of Vessels}

Determining the exact dates of chlorite vessels is a problem that will not be solved until further excavations are done in HalilRud River sites. The most important place scientifically excavated that play an essential role in chronology of these vessels is TepeYahya chlorite vessel workshop in IVB phase.

The date of this chlorite container production workshop dates back to Akkadian or post-Akkadian period or late third millennium B.C. centuries based on Pierre Amiet theories (Amiet, 1986, 133-134) consistent with the results of latest C14 examinations (Kohl, 2004, 286). In addition to TepeYahya, many samples of excavated findings have been found in Mesopotamia that helps in determining chronology. The samples found in Nippur, Adab, Ur and Mari show the periodical distribution of these vessels, a period starting from Early Dynastic I and IIand extending to the end of Akkad period and beyond. In fact, production of chlorite vessels spans a 500 year period, and they have been produced in various times, regions and workshops (Kohl, 2004, 286; Lamberg-Karlovsky, 1988, 54; Potts T.F, 1994, 255).

In addition, some of the vessels found in Mesopotamia bear inscriptions after production that can be a basis for termini ante quem dating. Typical examples of these vessels are war trophies ofAkkadian king to Rimush, bearing the theme Rimush, king of kings, conqueror of Elam and Parsumash. So these vessels are grouped in Akkadian period (Potts T.F, 1994, 225-232).

\section{Conclusions}

Although many of new chlorite findings are a result of unauthorized excavations, they indicate flourishing HalilRud River culture of the second half of the third millennium B.C. Although researchers have expressed different views and interpretations in this regard, today it is recognized that modification and change in them is necessary. Based on cultural material we able to recognize specialization in HalilRud basin and and has been in place for vessels production and trade to other regions.

In conclusion, it should be said that without doubt continuation of archeological explorations in HalilRud River direction, and identification of workshops and archeological contexts of containers along with study of other cultural materials especially seals and their impression, eliminates many of the arguments and ambiguities in this regard. In addition, in this regard there is a need to further study and evaluate the sites in the same horizon within and without the region such as TepeYahya IVB (Lamberg-Karlovsky, 2001), Bampoor I-IV (Cardi, 1970), Shahdad periods IV1-III2 (Hakemi, 1997) and Shahr-I-Sokhta II-III (Kohl, 1977, tab. 1; Sajjadi, 2003; Tosi, 1983), Susa V (Miroschedi, 1973, 9-77), Persian Gulf sites such as Tarut (Zarins, 1978, 65-93) and Mesopotamian sites such as Nippur, Adab, Ur and Mari (Lamberg-Karlovsky, 1988, 55-68). 


\section{REFERENCES}

[1] Amiet, P. (1986).L'âge des échanges inter-iraniens 3500-1700 avant J-C, Paris : Editions de la Réunion des musées nationaux.

[2] Cardi, B. De. (1970). Excavations at Bampur, A Third Millennium Settlement in Persian, Baluchistan, 1966.Anthropological Papers of the American Museum of Natural History: 513

[3] Cleuziou, P. S. (2003). Jiroft et Tarut, Dossiers de Archéologie, Jiroftfabuleusedécouverte en Iran (complete issue on Jiroft with articles by archaeologists, coordinated by J. Perrot and Y. Madjidzadeh), October: 114-125.

[4] Dumarcay, A. (1984). L Architecture de Mundigak, Bulletin De L Ecole Française D Extrême-Orient LXXIII : 47-80.

[5] Fouache, E. et al. (2005). La Vallee de Hallil Roud ( Region de Jiroft, Iran ), Paleorient 31/2: 104-122.

[6] Geographical atlas of Kerman Province.(2003). Tehran Ministry of Defense Publishing geographical organization and support the armed forces.

[7] Hakemi, A. (1997). Shahdad.Archaeological Excavations of a Bronze Age Center in Iran. Rom: ISMEO.

[8] Helwing, B. (2004). Eealy Towns in Iran, Persiens Antike Pracht: Katalog der Ausstellung des Deutschen Bergbau-Museum Bochum Band 1: 154-165.

[9] Jafari, A. (1997). Gytashnasy Iran: Iran's rivers and rivers, Vol. II, Tehran: Gita Press Organization Science Geography and Cartography.

[10] Kohl, P. L. (1974).Seeds of Upheaval: the production of chlorite at TepeYahya and an analysis of commodity production and trade in Southwest Asia in the mid-third millennium, Harvard University: Ph.D. dissertation Department of Anthropology.

[11] (1977). A Note on Chlorite Artifacts from Shahre-Sokhta, East and Vest 27: 111-127.

[12] (2004). Chlorite and Other Stone Vessels and their Exchange on the Iranian Plateau and Beyond, Persiens Antike Pracht: Katalog der Ausstellung des Deutschen Bergbau-Museum Bochum Band 1: 282-289.

[13] Lamberg-Karlovsky, C. C. (1988). The Intercultural Style Vessels, Iranica Antiqua XXIII, 45-95.
[14] (2001). Afterword. Excavations at TepeYahya: reconstructing the past, Excavations At TepeYahya, Iran 1967-1975: The Third Millennium: 269-280. Harvard: Harvard University Press.

[15] Madjidzade, Y. (2003). Jiroft, The earliest Oriental Civilization,Tehran: Ministry of Culture and Islamic Guidance.

[16] (2005). Presentation of the archaeological excavations at Jiroft: HalilRud Basin, Kerman (2003-2007), Tehran: ICHTO.

[17] Miroschedi, P. De.(1973). Vases et objets en steatite susiens du Musee du Louvre, Cahiers de la Délégation Archéologique Française en Iran 2:9-77.

[18] Muscarella, O.W. (2004). Jiroft and "Jiroft-Aratta" A Review Article of Yousef Madjidzadeh, Jiroft: The Earliest Oriental Civilization, Bulletin of the Asia Institute,www.bulletinasiainstitute.org

[19] Perrot, J. (2003). L Iconographie de Jiroft,Dossiers de Archéologie, Jiroftfabuleusedécouverte en Iran (complete issue on Jiroft with articles by archaeologists, coordinated by J. Perrot and Y. Madjidzadeh), October: 96-114.

[20] Perrot, J. and Madjidzadeh, Y. (2005). L Iconographie Des Vases Et Objets En Chlorite De Jiroft (Iran), Paleorient 31/2: 123-152.

[21] Piran, S. and M, Hesari.(2005).The catalogue of exhibition of select restituted objects, Tehran: Iran Bastan Museum.

[22] Potts, T.F. (1994). Mesopotamia and east: An archaeological and historicalstudy of foreign relations ca. $3400-2000$ B.C, Oxford: Oxford University Press.

[23] Sajjadi, S. M. (2003). Excavation at Shahr-I-Sokhta preliminary report on the excavation of graveyard 1997 2000, Iran 41: 21- 97

[24] Tossi, M. (1983).Prehistoric Sistan 1, IsMEO Reports and Memories 19, Rom: ISMEO.

[25] Vallat, P. J. (2003). La Ziggurat, Dossiers de Archéologie ,Jiroftfabuleusedécouverte en Iran (complete issue on Jiroft with articles by archaeologists, coordinated by J. Perrot and Y. Madjidzadeh), October: 92-96

[26] Zarins, J. (1978). Steatite Vessels in the Riyadh Museum, ATLAL 2: 65-93 